\title{
Maternal vgll4a promotes blastoderm cohesion enabling yap1-mediated mechano- transduction during zebrafish epiboly
}

\author{
Carlos Camacho-Macorra ${ }^{1,2}$, Noemí Tabanera ${ }^{1,2}$, Paola Bovolenta ${ }^{1,2, *}$ and Marcos $\mathbf{J}$
}

$$
\text { Cardozo }{ }^{1,2, *}
$$

${ }^{1}$ Centro de Biología Molecular Severo Ochoa, Consejo Superior de Investigaciones Científicas-Universidad Autónoma de Madrid, Madrid 28049, Spain. ${ }^{2}$ Centro de Investigación Biomédica en Red de Enfermedades Raras (CIBERER), Madrid 28049, Spain

*- Last co-authors

*Corresponding authors: pbovolenta@cbm.csic.es, mcardozo@cbm.csic.es

Running title: vgll4a function in epiboly progression

Keywords: yap signaling, Vgll4, vgll4a, actomyosin, E-cadherin complex, epiboly 
bioRxiv preprint doi: https://doi org/10.1101/2020 12 01.407478. this version posted December 4, 2020. The copyright holder for this

\begin{abstract}
Cellular cohesion provides tissue tension, which is then sensed by the cytoskeleton and decoded by the activity of mechano-transducers, such as the transcriptional cofactor Yap1, thereby enabling morphogenetic responses in multi-cellular organisms. How cell cohesion is regulated is nevertheless unclear. Here we show that, zebrafish epiboly progression, a prototypic morphogenetic event that depends on Yap activity, requires the maternal contribution of the proposed yap1 competitor vgll4a. In embryos lacking maternal/zygotic vgll4a (MZvgll4a), spreading epithelial cells are ruffled, blastopore closure is delayed and the expression of the yap1-mediator arhgap18 is decreased, impairing the actomyosin ring at the syncytial layer. Furthermore, rather than competing with Yap1, vgll4a coordinate the levels of the E-Cadherin/ $\beta$-catenin adhesion complex components at the blastomere plasma membrane and hence their actin cortex distribution. Taking these results together, we propose that maternal vgll4a may act at epiboly initiation to coordinate blastomere adhesion/cohesion, which is a fundamental piece of the self-sustained bio-mechanical regulatory loop underlying morphogenetic rearrangements during gastrulation.
\end{abstract}


bioRxiv preprint doi: https://doi.org/10.1101/2020.12.01.407478; this version posted December 4, 2020. The copyright holder for this preprint (which was not certified by peer review) is the author/funder, who has granted bioRxiv a license to display the preprint in perpetuity. It is made available under aCC-BY-NC-ND 4.0 International license.

\section{Introduction}

The three-dimensional organization of multicellular organisms requires morphogenetic tissue rearrangements, which are particularly evident during embryonic development or in pathological conditions, such as wound healing or cancer. These rearrangements are largely coordinated by the interplay among cell-cell interaction, mechanical forces, and signaling pathways, derived, in part, from the surrounding environment. The adaptive morphogenetic outcome critically depends on how the cells integrate and interpret this signal complexity and transmit the message to their nuclei, eliciting a consequent transcriptional response (Wozniak \& Chen, 2009).

In a number of organisms, including the teleost zebrafish, epiboly is the first morphogenetic rearrangement of gastrulating embryos (Bruce \& Heisenberg, 2020). These cellular rearrangements are relatively simple and, thus, have been often used to understand basic principles of morphogenesis (Bruce, 2016). Indeed, in zebrafish the blastoderm, positioned at the animal pole, is formed by a single layer of loosely packed epithelial cells, known as deep cell layer (DEL), which is covered by the so called epithelial enveloping layer (EVL). The blastoderm interfaces with an underlying epithelium, the yolk syncytial layer (YSL), itself a derivative of the blastoderm marginal cells. During epiboly, the blastoderm thins and moves toward the vegetal pole together with the external YSL (E-YSL). These epithelial spreading and thinning are driven, in part, by a circumferential actomyosin network formed by the E-YSL at its border with the EVL. The contraction of this actomyosin ring pulls the EVL to surround the yolk, further dragging the DEL toward the vegetal pole (Bruce, 2016). This process culminates at the end of gastrulation when the blastoderm seals around the yolk in a process known as blastopore closure (Bruce, 2016).

Different studies have shown that several morphogenetic events, including teleost epiboly, involve the function of the transcriptional co-activator Yes1 Associated Transcriptional Regulator (Yap1) and of the highly related TAZ. Yap1 was first described as a downstream nuclear effector of the Hippo signaling pathway, which is involved in the control of cell proliferation (Piccolo et al, 2014). However, there is evidence that Yap1 can operate, perhaps independently of Hippo signaling, as a mechano-transducer that links mechanical forces to cellular response (Totaro et al, 2018). Cells constantly probe the forces generated in their extracellular environment through plasma membrane adhesive proteins and internal tension adjustments executed 
bioRxiv preprint doi: https://doi.org/10.1101/2020.12.01.407478; this version posted December 4, 2020. The copyright holder for this preprint (which was not certified by peer review) is the author/funder, who has granted bioRxiv a license to display the preprint in perpetuity. It is made available under aCC-BY-NC-ND 4.0 International license.

by modifications of their actomyosin network. Upon increasing intracellular tension, Yap1, which is normally retained in the cytoplasm, translocates to the nucleus, where it binds to TEA domain (TEAD)-containing transcription factors (TEAD1-TEAD4). The derived complex activates the transcription of target genes, which include F-acting regulators and cell adhesion components, thereby promoting a positive feedback loop that enables cells to counterbalance the external mechanical forces to which they are exposed (Panciera et al, 2017).

In this context, recent studies have taken advantage of a yapl medaka (Oryzias latipes) mutant called hirame (hir), to show that yapl is required for epiboly progression by regulating the expression of arhgap18, a gene encoding a Rho GTPase activating protein involved in the contraction of the actomyosin ring at the E-YSL/EVL interface (Porazinski et al, 2015). What are the factors that modulate yap1 function during epiboly remained however without an answer. Here, we have asked if vestigiallike protein 4 (Vgll4) could be one of such factors.

Vgll4 is a transcriptional cofactor that can bind directly to TEAD proteins, via its tandem Tondu domain (TDU), thereby competing for the Yap-TEAD interaction and thus mechanistically acting as an inhibitor of Yap activity (Jiao et al, 2014; Koontz et al, 2013; Zhang et al, 2014). In Xenopus and zebrafish the transcripts of the different vgll4 paralogs show a dynamic developmental expression pattern in different tissues (Barrionuevo et al, 2014; Faucheux et al, 2010; Xue et al, 2018) and in zebrafish the mRNA of two (vgll4a; vgll4b) of the three paralogs (vgll4a, vgll4b and vgll4l) have been detected at the one cell stage (Xue et al, 2018), suggesting a possible early function. Although there are additional and species-specific phenotypes that affects later developing organs (Fillatre et al, 2019; Wang et al, 2020; Xue et al, 2019), loss of function studies in mice and analysis of genetic variants in the teleost Scatophagus argus suggest that vgll4 participate in the regulation of body size (Yu et al, 2019; Feng et al, 2019; Yang et al, 2020; Suo et al, 2020), a trait that is often altered as the consequence of an abnormal gastrulation.

By generating mutants for the three vgll4 paralogs in zebrafish, we demonstrate that instead of competing with yap1, as possibly expected, maternal but not zygotic vgll4a is required to sustain yap1 signaling, promoting blastomere cohesion and actomyosin contraction driving epiboly progression and normal zebrafish development. 


\section{Results}

\section{vgll4a function is required for proper epiboly progression}

To determine whether vgll4 genes contribute to zebrafish epiboly, we generated zebrafish lines in which vgll4a, vgll4b and vgll4l genes were mutated using CRISPRCas9 technology (Fig. S1a). Founders carrying frame-shift mutations for either one of the three vgll4 paralogs were selected in the F1 generation in order to obtain loss of function lines for each one of the existing Vgll4 proteins (Fig. S1b). Homozygous mutants for $v g l l 4 a, v g l l 4 b$ and $v g l l 4 l$ genes were obtained in F3. Their offspring was viable with no evident developmental phenotypes (Fig. S1c and data not shown). Similar results were obtained when adult vgll4a/vgll4b double mutants were analyzed (Fig. S1c).

$v g l l 4 a$ and $v g l l 4 b$ but not $v g l l 4 l$ transcripts are maternally expressed (Xue et al, 2018). We thus searched a possible phenotype in the F4 generation, in which vgll4a or vgll4b parental contribution will be no longer active. By intercrossing adults F3 vgll4a, vgll4b, vgll4l and vgll4a/vgll4b double mutant, we generated F4 embryos lacking both maternal and zygotic contribution of vgll4a (MZvgll4a), vgll4b (MZvgll4b), vgll4l (MZvgll4l) and vgll4a;vgll4b (MZvgll4a;MZvgll4b). The fertilization rate of the obtained heterozygous $M v g l l 4 a$ and $M v g l l 4 b$ embryos was significantly lower than that of wild type (wt), heterozygous vgll4a or heterozygous $v g l l 4 b$ embryos (Fig. S2 a-c). In contrast, the fertilization rate of $M v g l l 4 l$ heterozygous was similar to that of wt and heterozygous vgll4l embryos (Fig. S2d). This observation suggested that vgll4a and $v g l l 4 b$ maternal contribution could be important for oogenesis.

Besides the observed decrease in fertilization rate, viable MZvgll4a embryos appeared to progress through epiboly at a slower pace, with a delayed blastopore closure than wt embryos (Fig. 1a). To determine if the additional deficiency in maternal $v g l l 4 b$ contribution could enhance the phenotype of MZvgll4a embryos, we analyzed MZvgll4a;MZvgll4b double mutants, which however were no different from MZvgll4a embryos (Fig. 1a). Zebrafish mutants with slow epibolic movements present a decreased body length at larva stages (Sun et al, 2017). Consistent with this observation, the body length of MZvgll4a, MZvgll4b and MZvgll4a;MZvgll4b larvae at 3dpf was shorter than those of wt, whereas that of MZvgll4l larvae was very comparable (Fig. 1b).

To understand the possible reason of the MZvgll4a developmental delay, we stained the blastomere plasma membranes with antibodies against $\beta$-catenin. At sphere 
bioRxiv preprint doi: https://doi org/10.1101/2020.12.01.407478; this version posted December 4, 2020. The copyright holder for this preprint (which was not certified by peer review) is the author/funder, who has granted bioRxiv a license to display the preprint in perpetuity. It is made available under aCC-BY-NC-ND 4.0 International license.

stage, the mean area of individual DEL cells in MZvgll4a embryos was significantly smaller than that of wt (Fig. 1c-d) but it was then significantly larger as epiboly progressed (Fig. 1e, f). Similar cell size differences have been observed in mutants with slow epiboly, such as, for example, the E-cadherin mutants (Kane et al, 2005).

Together these data suggest that vgll4a and vgll4b function contributes to epiboly progression and their respective absence has consequences still visible at larva stages. Notably however, maternal vgll4a and vgll4b seem to act independently and cannot compensate each other function.

\section{Maternal but not zygotic vgll4a contribution is necessary for a timely development}

Many factors implicated in epiboly are maternally expressed (Lepage \& Bruce, 2010). The phenotype observed in MZvgll4a embryos was not observed in Zvgll4a mutant embryos obtained from heterozygous in-crosses (data not shown), suggesting that maternal but not zygotic vgll4a contributes to epiboly progression.

To test this possibility, we mated wt, heterozygous and mutant vgll4a fishes to generate larvae of different genotypes with or without $v g l l 4 a$ maternal contribution (Fig. $2 \mathrm{a}, \mathrm{c})$. Determination of the body length of the resulting larvae showed that, similarly to MZvll4a, $\mathrm{Mvgll}^{+/-}$embryos had an antero-posterior axis shorter than that of $v g l l 4 a^{+/-}$ and wt embryos (Fig. 2b). This indicates that zygotic vgll4a cannot compensate for the lack of its maternal function. To demonstrate that maternal $v g l l 4 a$ is indeed sufficient, we crossed vgll4a mutant males with vgll4a heterozygous females and vgll4a heterozygous males with vgll4a mutant females to obtain Zvgll4a and MZvgll4a embryos, with or without maternal vgll4 contribution, respectively (Fig. 2c). Notably, the body length of the resulting Zvgll4a larvae at 3dpf was very comparable to that of wt (Fig. 2d), indicating that the observed developmental delay is linked exclusively to the absence of $v g l l 4 a$ maternal contribution.

We next asked if vgll4b had a similar maternally restricted function. However, whereas $M Z v g l l 4 b$ are significantly shorter than wt, the body length of $M v g l l 4 b^{+/}$larvae was undistinguishable from that of wt (Fig. S3). This suggests that zygotic vgll4b can compensate for its maternal function.

To verify that the phenotype observed in MZvgll4a larva is directly linked to the absence of the maternally inherited mRNA/protein, we attempted to rescue MZvgll4a embryonic growth by injecting either the vgll4a-HA mRNA, its mutated version or the human VGLL4 protein in one cell stage embryos (Fig. S4a). None of the two mRNAs 
bioRxiv preprint doi: https://doi org/10.1101/2020.12.01.407478; this version posted December 4, 2020. The copyright holder for this preprint (which was not certified by peer review) is the author/funder, who has granted bioRxiv a license to display the preprint in perpetuity. It is made available under aCC-BY-NC-ND 4.0 International license.

could rescue the growth of the mutant embryos (Fig. S4b), despite the presence of the HA-tagged protein in the blastomeres as determined by immunofluorescent staining (Fig. S4c, d). Injection of recombinant human VGLL4 protein instead partially rescued the growth of MZvgll4a embryos (Fig. S4e), likely because its immediate availability can compensate for the maternal component.

Taken altogether, these observations demonstrate that maternal, but not zygotic, vgll4a is essential for timely embryonic development.

\section{Vgll4a sustains yap1 signaling to promote embryonic development}

Vgll4 competes with Yap1 for TEAD binding in different biological contexts, thereby antagonizing its signaling (Jiao et al, 2014; Koontz et al, 2013; Zhang et al, 2014). According to this mechanism, the MZvgll4a mutants should present an over-activation of Yap signaling and thus, Yap inhibition should rescue the MZvgll4a phenotype.

Verteporfin acts as an efficient inhibitor of YAP-TEAD interaction, reducing Yap1 signaling in different models (Liu-Chittenden et al, 2012), including the zebrafish (Fillatre et al, 2019; Grampa et al, 2016). We thus soaked wt and the MZvgll4 embryos in verteporfin from the one cell stage up to 8hpf and thereafter let the embryos develop in fresh medium until 3 days, when their body length was measured (Fig. 3a). Wt and MZvgll4l body size was reduced (Fig. 3b, c) to an extent similar to that of MZvgll4a larvae (Fig. 1b). Notably instead, verteporfin treatment had no effect on the length of MZvgll4a and MZvgll4a;MZvgll4b larvae, which were undistinguishable from their respective untreated controls (Fig. 3d, e). This suggests that Vgll4a and Yap1 do not compete but rather pull in the same direction. To verify this possibility, we asked if Yap signaling was decreased in MZvgll4a embryos, using the expression levels of the Yap1 targets $c c n 1$ and $c c n 2$ as read-outs (Zhang et al, 2011). qPCR analysis showed that at sphere stage $c c n l$ transcripts in MZvgll4a embryos were significantly reduced compared to wt, although this difference was no longer evident at 75\% epiboly stages (Fig. 3f, g). The $c c n 2 a$ and $c c n 2 b$ mRNAs were undetectable at these stages (data not shown).

Altogether these data indicate that maternal $v g l l 4 a$ is required to sustain yap1 signaling during zebrafish gastrulation.

\section{Maternal vgll4a is required for constriction of the actomyosin ring during epiboly}

Loss or knockdown of yap in medaka, zebrafish and Xenopus embryo causes a delay in blastopore closure (Gee et al, 2011; Porazinski et al, 2015). Further in the medaka fish 
bioRxiv preprint doi: https://doi org/10.1101/2020.12.01.407478; this version posted December 4, 2020. The copyright holder for this preprint (which was not certified by peer review) is the author/funder, who has granted bioRxiv a license to display the preprint in perpetuity. It is made available under aCC-BY-NC-ND 4.0 International license.

yap mutant, hirame (hir), this delay is associated with a reduced actomyosin-mediated tissue tension, as also observed after the combined knockdown of yap and taz in zebrafish (Porazinski et al, 2015). Furthermore, in hir mutants the expression of the Yap signaling effector, arhgap18, which controls tissue tension, is downregulated (Porazinski et al, 2015).

We thus reasoned that if maternal vgll4a sustain yap1 signaling, the MZvgll4a phenotype should be also associated with alterations of the actomyosin ring and a reduction of the epibolic arhgap18 expression. Indeed, in MZvgll4a embryos, the actomyosin ring was thinner (Fig. 4a-b', e) and the DEL and EVL margins more separated than those of wt embryos (Fig. 4a-b', f). The contour of EVL cells close to the EVL margin was also irregular with evaginations that resembled lamellipodia structures and loss of cellular contacts (Fig. 4c-d'). Furthermore, and similarly to the hir mutants, the transcript levels of arhgap18 were reduced as compared to those of wt (Fig. 4g).

Taken together these observations support the idea that vgll4a function is a requisite for yap1-dependent actomyosin ring contractibility and thus epiboly progression.

\section{Maternal vgll4a promotes E-cadherin/ $\beta$-catenin distribution at the blastomere plasma membrane}

Cells probe tension through plasma membrane proteins and then transmit the information to mechano-sensors such as Yap1 by means of cytoskeletal rearrangements (Panciera et al, 2017). Given that maternal vgll4a seemed to act upstream of yap1, we hypothesized that its activity could regulate blastomere adhesion and thus their tension probing capacity. Indeed, in cancer cells VGLL4 regulates the transcription of Ecadherin (Li et al, 2015; Song et al, 2019) and the E-cadherin/ $\alpha$-Catenin/ $\beta$-Catenin adhesion complex is an upstream regulator of Yap1 in different biological contexts (Kim et al, 2011; Schlegelmilch et al, 2011; Silvis et al, 2011). Furthermore, the epibolic phenotype of MZvgll4a embryos resembled that of the pou5fl/Oct4 deficient MZspg embryos (Lachnit et al, 2008; Song et al, 2013). In these mutants, deep cells move with a considerable delay in relation to the actin-depleted EVL margin, EVL cells form an abnormal number of lamellipodia (Lachnit et al, 2008; Song et al, 2013) and present a defective E-cadherin endosomal trafficking in blastomeres (Song et al, 2013). We thus compared the distribution of F-actin, $\beta$-catenin and E-Cadherin in wt and MZvgll4a embryos, as read outs of blastomere cohesion (Yap et al, 2018). 
bioRxiv preprint doi: https://doi org/10.1101/2020.12 01.407478; this version posted December 4,2020. The copyright holder for this

F-actin, $\beta$-catenin and, to a lesser extent, E-cadherin signal intensity of MZvgll4a EVL cells was significantly decreased at sphere stage (Fig. 5a-h). These changes were less evident in DEL cells, where only $\beta$-catenin was significantly reduced at sphere (Fig. 5i-p) and shield (Fig. S5) stages. Notably, the overall E-cadherin mRNA expression levels (cdhl) in wt and MZvgll4a embryos were similar at both sphere and shield stage (Fig. S6a, c). $\beta$-catenin acts as an effector of Wnt signaling and thus its decreased levels at the plasma membrane could be a consequence of an over-activation of the pathway. To test this possibility, we determined the expression levels of different Wnt targets and read-outs. No difference was observed in the levels of axin1, axin2 and lefl expression between MZvgll4a and wt embryos at both sphere and shied stage (Fig. S6b, d).

All in all, these data indicate that maternal vgll4a promotes E-cadherin/ $\beta$-catenin localization at the blastomeres' plasma membrane and hence their actin cortex distribution. Blastomere cohesion, in turn, enables yap1-mediated mechanotransduction and actomyosin ring constriction driving epiboly progression. 


\section{Discussion}

The genome of a fertilized egg is transcriptionally inactive. Thus, the RNAs and proteins deposited in the eggs by the mother are responsible for coordinating the first morphogenetic events that takes place during gastrulation, initially single-handed and then in cooperation with the increasingly available zygotic gene products (SolnicaKrezel, 2020). In the zebrafish egg, these maternally derived molecules represent a large proportion of all possible gene products (Harvey et al, 2013). However, how many of them are critical for epiboly initiation and progression is still poorly defined. Genome wide (Kane et al, 1996) and specific maternal-effect mutational screens in zebrafish have identified only a limited number of mutants with an epiboly phenotype (Wagner et al, 2004; Dosch et al, 2004) and their subsequent characterization supported an important contribution of adhesion molecules and cytoskeletal components (Bruce, 2016). Other studies have thereafter identified a few maternally inherited transcriptional regulators, including eomes, foxh1, pou5fl/oct4, nanog and yap1 (Bruce et al, 2005; Reim \& Brand, 2006; Pei et al, 2007; Lachnit et al, 2008; Song et al, 2013; Porazinski et al, 2015; Veil et al, 2018; Gagnon et al, 2018). In this still fragmented scenario, our study adds a new component to the genetic network coordinating zebrafish epiboly, showing an important role for maternally inherited vgll4a, and, in part, for its paralog vgll4b. Notably, it also shows that vgll4a is required to support, rather than antagonise, yap1 signalling and to coordinate blastomere adhesion/cohesion. Our data further confirm that this cohesion is a fundamental piece of the self-sustained bio-mechanical regulatory loop underlying epibolic morphogenetic rearrangements, which culminates with blastopore closure at the end of gastrulation.

Zebrafish epiboly can be divided in two phases: initiation or doming and progression. As a limitation, our study does not clearly define the spatio-temporal window in which vgll4a activity is required. However, the large majority of factors implicated in doming are maternally expressed, as both $v g l l 4 a$ and $v g l l 4 b$ are (Xue et al, 2018). This may place their activity at epiboly initiation even if the phenotypic consequences of their inactivation are observed only later. Such a time-lag has been indeed reported for other factors contributing to epiboly initiation (Lachnit et al, 2008; Sun et al, 2017). A recent study has shown that at sphere stage the central blastula becomes "fluid" as a consequence of loss of cell-cell adhesion and increased cell division (Petridou et al, 2019). The blastoderm margins instead maintain cell-cell 
bioRxiv preprint doi: https://doi.org/10.1101/2020.12.01.407478; this version posted December 4, 2020. The copyright holder for this preprint (which was not certified by peer review) is the author/funder, who has granted bioRxiv a license to display the preprint in perpetuity. It is made available under aCC-BY-NC-ND 4.0 International license.

adhesion and thus tension thanks to the activity of Wnt11 non-canonical signalling (Petridou et al, 2019), known to control E-cadherin availability at the plasma membrane (Ulrich et al, 2005). If this differential fluid vs tense state is perturbed, the ability of the blastula to react to mechanical forces is altered and epiboly becomes defective (Petridou et al, 2019). The phenotype of MZvgll4a mutants could be explained within this frame. We show that vgll4a role in epiboly can be considered as strictly maternal (SolnicaKrezel, 2020) and thus could likely act upstream of Wnt11 signalling. Vgll4a-mediated control of Wnt signalling will impinge on E-cadherin/ $\beta$-catenin availability at the plasma membrane and thus differential blastoderm viscosity critical for epiboly progression. In support of this possibility, vgll4 paralogs have been shown to control the expression of non-canonical Wnt signaling components, including wnt11, fzd8a and fzd10 (Fillatre et al, 2019). Alternatively, vgll4a could interfere with non-canonical Wnt signaling indirectly through the regulation of Wnt/ $\beta$-catenin canonical pathway, as the two branches of the pathway have been previously shown to have antagonistic effects in morphogenesis (Cavodeassi et al, 2005). Indeed, VGLL4 seems to interfere with the formation of a TEAD4-TCF4 complex, which promotes cell proliferation in colorectal cancer (Jiao et al, 2017). Furthermore, VGLL4 overexpression suppresses nuclear $\beta$ catenin levels and inhibits migration and invasion of gastric cancer cells, while its inactivation has opposite effects ( $\mathrm{Li}$ et al, 2015). As an additional possibility, vgll4a could directly regulate E-cadherin expression as observed in both gastric and breast cancers (Li et al, 2015; Song et al, 2019), thereby influencing the membrane levels of E-cadherin/ $\beta$-catenin complexes. According to our data the latter possibilities are however less likely. We observed a small, although significant, decrease of E-cadherin membrane localization only in EVL cells of MZvgll4a embryos at sphere stage, and no significative changes in the mRNA levels of $c d h l$ or in those of three read-out of $\mathrm{Wnt} / \beta$-catenin signalling. However, our analysis was performed using the entire embryos, precluding the identification of changes occurring only in a small subset of the cells. Furthermore, we cannot rule out that the MZvgll4a phenotype might be associated with E-cadherin destabilization or alteration of its trafficking, as reported for the zebrafish wnt11/slb and oct4/MZspg mutants (Song et al, 2013; Petridou et al, 2019).

Although our study focuses on $v g l l 4 a$, we report that the related $v g l l 4 l$ has no role in epiboly, consistent with its lack of early expression (Xue et al, 2018) and its suggested functional diversification (Fillatre et al, 2019). On the contrary, we show both $v g l l 4 a$ and $v g l l 4 b$ seem to be important for oocyte fecundity and that MZvgll4b and 
bioRxiv preprint doi: https://doi.org/10.1101/2020.12.01.407478; this version posted December 4, 2020. The copyright holder for this preprint (which was not certified by peer review) is the author/funder, who has granted bioRxiv a license to display the preprint in perpetuity. It is made available under aCC-BY-NC-ND 4.0 International license.

MZvgll4a mutants present a very comparable developmental delay. This indicates that $v g l l 4 b$ has also an important role in both oocyte and gastrulation. However, in contrast to what observed for $v g l l 4 a$, maternal vgll4b activity can be compensated by its zygotic counterpart. Furthermore, MZvgll4a;MZvgll4b double mutants are phenotypically very comparable to the two single mutants, suggesting that the two paralogs do not compensate each other function and perhaps act in a different spatio-temporal window that converges in the same shorter axis phenotype. At later stages of development, vgll4b has been implicated in erythropoiesis, terminal differentiation (Wang et al, 2020), heart valvulogenesis (Xue et al, 2019) and establishment of the left-right asymmetry in coordination with vgll4l (Fillatre et al, 2019). Our vgll4a mutants do not show traits linked to similar functions, at least in a gross morphological analysis, further supporting a possible diversification of the paralog activity.

Vgll4 has been initially described as co-transcriptional repressor that interacts with Tead transcription factors, thereby acting as an as antagonist of Yap signalling (Guo et al, 2013; Zhang et al, 2014). This function has been thereafter validated in multiple contexts especially in tumour development (Yamaguchi, 2020). Our study not only shows that maternal vgll4a is required for epiboly but also that it does so supporting rather than antagonising yap1 signalling. The generation of a transgenic Yap/Taz-Tead reporter zebrafish line faithfully highlights pathway activation from $22 \mathrm{hpf}$ (Miesfeld \& Link, 2014). Using this same line we have been unable to detect reporter expression at epiboly stages and have thus used alternative approaches to determine yap1 signalling, including the expression of the yap1 downstream target ccnl and embryonic treatment with verteroporfin. These approaches show a decreased yap1 signalling in MZvgll4a mutants and support a possible role of vgll4a upstream of yap1, as we have proposed above. However, our analysis has been performed at the scale of the whole embryo, taking epiboly progression, actomyosin organization and cell cohesion as read-out of vgll4a function in morphogenetic rearrangement. These rearrangements however highly depend on mechanical and biochemical events at the cellular and subcellular scale (Stooke-Vaughan \& Campàs, 2018; Petridou et al, 2017). In this scenario, we cannot exclude that the delay in epiboly progression observed in MZvgll4a embryos represents the macroscopic result of a series of mechano-chemical feedback loops at the cellular scale (Hannezo \& Heisenberg, 2019), involving both vgll4a and yap1 in the same or even different cell populations. 
bioRxiv preprint doi: https://doi org/10.1101/2020 12 01.407478. this version posted December 4, 2020. The copyright holder for this

Nevertheless, and independently of the relative position of vgll4a and yap1 in epiboly regulation, our data clearly show that vgll4a is required for a proper balance between tissue tension/cohesion and contractibility, two factors that contribute to mechanical stress (Wozniak \& Chen, 2009). Thus, in the absence of vgll4a, cellular cohesion mediated by adhesion complexes is poor, impairing embryonic mechanosensation (Fig. 6). This impairment decreases yap-dependent mechano-transduction, which, in turn, affects the contraction of the actomyosin network, delaying epiboly progression (Fig. 6).

In a broader context, our data suggest that up-regulation of Vgll4 expression may serve to enhance the mechano-sensing properties of some tissues, perhaps restoring an unbalanced back-and-forth dialogue between biochemical and mechanical cues, which has been described in pathological conditions, including different type of primary and metastatic cancers (Deng \& Fang, 2018). 
bioRxiv preprint doi: https://doi org/10.1101/2020.12.01.407478; this version posted December 4, 2020. The copyright holder for this preprint (which was not certified by peer review) is the author/funder, who has granted bioRxiv a license to display the preprint in perpetuity. It is made available under aCC-BY-NC-ND 4.0 International license.

\section{Materials and methods}

Maintenance of fish lines. Adult AB/TUE wild type and mutant (vgll4a, vgll4b, vgll4l) zebrafish were maintained at $28^{\circ} \mathrm{C}$ on $14 / 10 \mathrm{~h}$ light/dark cycle. Embryos were raised at $28^{\circ} \mathrm{C}$ and staged according to the hours post fertilization (hpf) and their morphology. Embryos were growth in $\mathrm{E} 3$ medium $\left(\mathrm{NaCl}, 5 \mathrm{mM} ; \mathrm{KCl}, 0.17 \mathrm{mM} ; \mathrm{CaCl}_{2}, 0.33 \mathrm{mM}\right.$; $\mathrm{MgSO}_{4}, 0.33 \mathrm{mM} ; 5,10 \%$ Methylene Blue). The ethical committee for Animal Experimentation of the Consejo Superior de Investigaciones Científicas (CSIC) and of the Comunidad Autónoma de Madrid approved the procedures used in the study.

Zebrafish mutants generation. Zebrafish mutant lines were generated using CRISPR/Cas9 technology. The gRNA were designed using the CHOP-CHOP tool (Labun et al, 2019) looking for potential disruption of enzyme restriction sites. gRNAs were synthesized using PCR templates as described in (Varshney et al, 2016). Cas9 protein (300 ng/ $\mu \mathrm{L}$; EnGen ${ }^{\circledR}$ Spy Cas9 NLS, New England Biolabs) and gRNAs (100 ng/ $\mu 1$; Table S1) were co-injected into one-cell stage zebrafish embryos. F0 embryos were raised and outcrossed with $\mathrm{AB} / \mathrm{TUE}$ wt. PCR amplification on genomic DNA isolated from tail clips of F1 zebrafish embryos was performed to identify disruption of specific restriction sites (Table S2). The DNA of potential mutants was thereafter sequenced and the selected embryos were raised to adulthood. We selected mutants in which the reading frame was disrupted and truncated as follow: vgll4a-S85Mfs 15 , $v g l l 4 b$-P156Rfs5 and $v g l l 4 l$ P111Hfs61 (see Fig. S1 for more details).

Embryo injections. Zebrafish embryos were injected at the one cell stage using a IM300/Narishige microinjector. Recombinant humanVGLL4 protein $(0.19 \mathrm{ug} / \mu \mathrm{l}$; Abnova, Ref: H00009686-P01) and vgll4a-HA mRNA (100 $\mathrm{ng} / \mu \mathrm{l})$ were used in rescue experiments. Phosphate buffer saline (PBS) containing $0.1 \%$ BSA or mutated vgll4aHA mRNA (cloned from the vgll4a-S85Mfs 15 line) were injected as controls.

Tissue processing and immunochemistry. Embryos were fixed by immersion in $4 \%$ paraformaldehyde in $0.1 \mathrm{M}$ phosphate buffer $\mathrm{pH} 7.2(\mathrm{wt} / \mathrm{vol})$ overnight at $4{ }^{\circ} \mathrm{C}$. Embryos were then washed in PBS with $0.5 \%$ Triton-X-100, incubated in a $15 \%$ sucrose-PBS solution (wt/vol), embedded and frozen in a $7.5 \%$ gelatin in $15 \%$ sucrose solution (wt/vol). Cryostat sections or whole embryos were stained using standard protocols and antibodies against the following antigens: HA (1:250, Sigma), $\beta$-catenin (1:300, BD Bioscience) and E-cadherin (1:300, BD Bioscience). Incubation with phalloidin (1:200, 
bioRxiv preprint doi: https://doi.org/10.1101/2020.12.01.407478; this version posted December 4, 2020. The copyright holder for this preprint (which was not certified by peer review) is the author/funder, who has granted bioRxiv a license to display the preprint in perpetuity. It is made available under aCC-BY-NC-ND 4.0 International license.

Sigma) was used to detect actin. Incubation with appropriate secondary antibodies was performed following standard procedures.

vgll4a-HA cloning. vgll4a was amplified from cDNA of wt or MZvgll4a (as control) embryos using the following primers (Fw: 5'-GGAATCAACAGTTAGCGTGCT-3'; Rv: 5'-aaCTCGAGTCAAGCGTAATCTGGAACATCGTATGGGTAAGACTGACC AACATGATTG-3'). The amplicon, which includes the hemagglutinin (HA) epitope, was cloned by TA-cloning in the pSC-A vector using the StrataClone PCR Cloning Kit (Agilent). The vgll4a-HA fragment was thereafter obtained from the pCS-A construct using EcoRI/XhoI digestion and cloned in the pCS2 vector. The pCS2 construct, linearized with NotI, was used to synthesize mRNA from the wt or mutated vgll4a version, tagged with HA, using the mMESSAGE mMACHINE SP6 Transcription kit (Invitrogene) following manufacturer's instructions. After transcription, mRNAs were purified using the NucleoSpin ${ }^{\circledR}$ RNA Clean-up kit (Machery Nagel).

Quantitative RT-PCR analysis. Total RNA was isolated from wt and mutant embryos ( $n=30$, for each genotype) using TRIzol (Sigma) according to the manufacturer's instruction. Each experiment was performed with biological triplicates. $5 \mu \mathrm{g}$ of total RNA was used to synthesize the first-strand cDNA using the First-Strand cDNA synthesis kit (GE Healthcare) with a $\mathrm{pd}(\mathrm{N})_{6}$ primer. Each quantitative RT-qPCR reaction was performed using the GoTaq qPCR Master Mix kit (Promega). For a $10 \mu \mathrm{l}$ reaction, $4 \mu \mathrm{l}$ of cDNA $(2.5 \mathrm{ng} / \mu \mathrm{l})$ was mixed with $1 \mu \mathrm{l}$ of primers $(2.5 \mu \mathrm{M}$; Table S3) and $4 \mu 1$ master mix. Reaction was incubated at $95^{\circ} \mathrm{C}$ for $10 \mathrm{~min}$, then at $95^{\circ} \mathrm{C}$ for $15 \mathrm{~s}$ and 40 cycles and at $60^{\circ} \mathrm{C}$ for $60 \mathrm{~s}$. The levels of the eeflalll mRNA were used as housekeeping reference (Xu et al, 2016).

Pharmacological treatment. Embryos were incubated at $28^{\circ} \mathrm{C}$ from the one cell stage to $75 \%$ epiboly $(8 \mathrm{hpf})$ in $\mathrm{E} 3$ medium containing $5 \mu \mathrm{M}$ of the Yap1 antagonist verteporfin (5305, Tocris) dissolved in DMSO or the same volume of DMSO as control.

Imaging. Sections were analysed with DM or confocal microscope. Zebrafish embryos at different stages were observed and photographed using a stereomicroscope and DFC500, DFC350 FX cameras (Leica Microsystems). For sections or whole embryo staining, LSM710 confocal laser scanning microscope coupled to an AxioObserver inverted microscope (Zeiss) were used to obtain digital images, which were then 
bioRxiv preprint doi: https://doi.org/10.1101/2020.12.01.407478: this version posted December 4, 2020. The copyright holder for this preprint (which was not certified by peer review) is the author/funder, who has granted bioRxiv a license to display the preprint in perpetuity. It is made available under aCC-BY-NC-ND 4.0 International license.

processed and analysed with ImageJ (Fiji) software. Images shown in Figures 1, 4, 5, S1, S2, S4 and S6 were assembled using the Photoshop CS5 software.

Quantification and statistical analysis. All quantifications were performed using the ImageJ (Fiji) software. 72hpf embryonic larvae were treated with tricaine and photographed in lateral views at $13 \mathrm{X}$ magnification to determine their body length. The area of individual and centrally positioned blastoderm cells from wt and mutant embryos was determined by tracing their perimeter on confocal images of whole embryos stained with $\beta$-catenin antibody. Only one image per embryo was used. The position and width of the actomyosin ring was determined on z-stack files obtained from the confocal images of whole embryos. The z-stack files were used to generate maximum intensity projections. The mid-region of the actomyosin ring and DEL/EVL margins were positioned in the centre of the image to avoid possible visual distortions due to the embryo curvature and the region of interest (ROI) was selected. Ten different measurements of the width of the actomyosin ring as well as the distance between DELEVL were obtained along the ROI using the "straight" selection tool. The ten measurement per embryo were averaged to obtain a more accurate value and their mean was used in the comparative analysis. Immunofluorescence intensity quantifications were performed using mid-plane of z-stack files obtained from the confocal imaging of $\beta$-catenin, F-actin and E-cadherin staining on whole embryos (EVL cells) or cryostat sections of different embryos (DEL cells). A rectangular ROI was used to measure the mean gray value of the selected image as indicator of signal intensity. GraphPad Prism 7 statistic software was used to analyze the data using t-test for two groups with parametric distribution and with Mann-Whitney test for two groups with no parametric distribution. One-way ANOVA test was used for more than two groups with parametric distribution and Kruskal-Wallis test for no parametric distribution. Statistical difference between pools of treated and control embryos was determined with the Pearson's X2 test. Violin-plots in Figure 1 were obtained with the R-software and the ggplot2 package. Error bars indicate s.e.m. in all graphs. 
bioRxiv preprint doi: https://doi org/10.1101/2020 12 01.407478. this version posted December 4, 2020. The copyright holder for this

Acknowledgements: We wish to acknowledge the excellent technical assistance of Alfonso Gutierrez Garcia in the fish facilities and the staff of the CBMSO Image analysis and Genomic and Next Generation Sequencing facilities. This work was supported by grants from the Spanish MINECO (BFU2016-75412-R with FEDER funds); AEI (PID2019-104186RB-I00 and RED2018-102553-T) and a grant from the Fundación Ramon Areces to PB. CCM and MJC are supported by predoctoral contract from the CIBERER and a Juan de la Cierva postdoctoral contract from the AEI (IJCI2016-27683), respectively. A CBM Institutional grant from the Fundación Ramon Areces is also acknowledged.

Competing interest: The authors declare no competing interests.

Author contributions. CCM, MJC and PB conceptualized and designed the research study. CCM performed most of the experiments, acquired and analyzed the data. NT generated data reported in Fig. 1, 5 and Fig. S4, S6 and MJC those in Fig. 1, 4, 5 and Fig. S5. PB obtained financial support. CCM, MJC and PB wrote the paper. All authors read and approved the manuscript. 
bioRxiv preprint doi: https://doi org/10.1101/2020.12.01.407478; this version posted December 4, 2020. The copyright holder for this

\section{References}

Barrionuevo M-G, Aybar MJ \& Tríbulo C (2014) Two different vestigial like 4 genes are differentially expressed during Xenopus laevis development. Int J Dev Biol 58: 369-377

Bruce AEE (2016) Zebrafish epiboly: Spreading thin over the yolk. Dev Dyn 245: 244-258

Bruce AEE \& Heisenberg C-P (2020) Chapter Eleven - Mechanisms of zebrafish epiboly: A current view. In Current Topics in Developmental Biology, Solnica-Krezel L (ed) pp 319341. Academic Press

Bruce AEE, Howley C, Fox MD \& Ho RK (2005) T-Box Gene eomesodermin and the Homeobox-Containing Mix/Bix Gene mtx2 Regulate Epiboly Movements in the Zebrafish. Dev Dyn Off Publ Am Assoc Anat 233: 105-114

Cavodeassi F, Carreira-Barbosa F, Young RM, Concha ML, Allende ML, Houart C, Tada M \& Wilson SW (2005) Early stages of zebrafish eye formation require the coordinated activity of Wnt11, Fz5, and the Wnt/beta-catenin pathway. Neuron 47: 43-56

Deng X \& Fang L (2018) VGLL4 is a transcriptional cofactor acting as a novel tumor suppressor via interacting with TEADs. Am J Cancer Res 8: 932-943

Dosch R, Wagner DS, Mintzer KA, Runke G, Wiemelt AP \& Mullins MC (2004) Maternal control of vertebrate development before the midblastula transition: mutants from the zebrafish I. Dev Cell 6: 771-80

Faucheux C, Naye F, Treguer K, Fedou S, Thiebaud P \& Theze N (2010) Vestigial like gene family expression in Xenopus: common and divergent features with other vertebrates. Int $J$ Dev Biol 54: 1375-82

Feng X, Wang Z, Wang F, Lu T, Xu J, Ma X, Li J, He L, Zhang W, Li S, et al (2019) Dual function of VGLL4 in muscle regeneration. EMBO J 38: e101051

Fillatre J, Fauny JD, Fels JA, Li C, Goll M, Thisse C \& Thisse B (2019) TEADs, Yap, Taz, Vgll4s transcription factors control the establishment of Left-Right asymmetry in zebrafish. Elife 8

Gagnon JA, Obbad K \& Schier AF (2018) The primary role of zebrafish nanog is in extraembryonic tissue. Development 145

Gee ST, Milgram SL, Kramer KL, Conlon FL \& Moody SA (2011) Yes-Associated Protein 65 (YAP) Expands Neural Progenitors and Regulates Pax3 Expression in the Neural Plate Border Zone. PLOS ONE 6

Grampa V, Delous M, Zaidan M, Odye G, Thomas S, Elkhartoufi N, Filhol E, Niel O, Silbermann F, Lebreton C, et al (2016) Novel NEK8 Mutations Cause Severe Syndromic Renal Cystic Dysplasia through YAP Dysregulation. PLOS Genet 12: e1005894

Guo T, Lu Y, Li P, Yin M-X, Lv D, Zhang W, Wang H, Zhou Z, Ji H, Zhao Y, et al (2013) A novel partner of Scalloped regulates Hippo signaling via antagonizing Scalloped-Yorkie activity. Cell Res 23: 1201-1214

Hannezo E \& Heisenberg C-P (2019) Mechanochemical Feedback Loops in Development and Disease. Cell 178: 12-25

Harvey SA, Sealy I, Kettleborough R, Fenyes F, White R, Stemple D \& Smith JC (2013) Identification of the zebrafish maternal and paternal transcriptomes. Development 140: 2703-2710

Jiao S, Li C, Hao Q, Miao H, Zhang L, Li L \& Zhou Z (2017) VGLL4 targets a TCF4-TEAD4 complex to coregulate Wnt and Hippo signalling in colorectal cancer. Nat Commun 8: 14058

Jiao S, Wang H, Shi Z, Dong A, Zhang W, Song X, He F, Wang Y, Zhang Z, Wang W, et al (2014) A Peptide Mimicking VGLL4 Function Acts as a YAP Antagonist Therapy against 
bioRxiv preprint doi: https://doi org/10.1101/2020.12.01.407478: this version posted December 4, 2020. The copyright holder for this preprint (which was not certified by peer review) is the author/funder, who has granted bioRxiv a license to display the preprint in perpetuity. It is made available under aCC-BY-NC-ND 4.0 International license.

Gastric Cancer. Cancer Cell 25: 166-180

Kane DA, Hammerschmidt M, Mullins MC, Maischein H-M, Brand M, Van Eeden FJM, Furutani-Seiki M, Granato M, Haffter P, Heisenberg C-P, et al (1996) The zebrafish epiboly mutants. Development 123: 47-55

Kane DA, McFarland KN \& Warga RM (2005) Mutations in half baked/E-cadherin block cell behaviors that are necessary for teleost epiboly. Dev Camb Engl 132: 1105-1116

Kim N-G, Koh E, Chen X \& Gumbiner BM (2011) E-cadherin mediates contact inhibition of proliferation through Hippo signaling-pathway components. Proc Natl Acad Sci 108: 1193011935

Koontz LM, Liu-Chittenden Y, Yin F, Zheng Y, Yu J, Huang B, Chen Q, Wu S \& Pan D (2013) The Hippo Effector Yorkie Controls Normal Tissue Growth by Antagonizing ScallopedMediated Default Repression. Dev Cell 25: 388-401

Labun K, Montague TG, Krause M, Torres Cleuren YN, Tjeldnes H \& Valen E (2019) CHOPCHOP v3: expanding the CRISPR web toolbox beyond genome editing. Nucleic Acids Res 47: W171-W174

Lachnit M, Kur E \& Driever W (2008) Alterations of the cytoskeleton in all three embryonic lineages contribute to the epiboly defect of Pou5f1/Oct4 deficient MZspg zebrafish embryos. Dev Biol 315: 1-17

Lepage SE \& Bruce AEE (2010) Zebrafish epiboly: mechanics and mechanisms. Int J Dev Biol 54: $1213-1228$

Li H, Wang Z, Zhang W, Qian K, Liao G, Xu W \& Zhang S (2015) VGLL4 inhibits EMT in part through suppressing $\mathrm{Wnt} / \beta$-catenin signaling pathway in gastric cancer. Med Oncol Northwood Lond Engl 32: 83

Liu-Chittenden Y, Huang B, Shim JS, Chen Q, Lee S-J, Anders RA, Liu JO \& Pan D (2012) Genetic and pharmacological disruption of the TEAD-YAP complex suppresses the oncogenic activity of YAP. Genes Dev 26: 1300-1305

Miesfeld JB \& Link BA (2014) Establishment of transgenic lines to monitor and manipulate Yap/Taz-Tead activity in zebrafish reveals both evolutionarily conserved and divergent functions of the Hippo pathway. Mech Dev 133: 177-88

Panciera T, Azzolin L, Cordenonsi M \& Piccolo S (2017) Mechanobiology of YAP and TAZ in physiology and disease. Nat Rev Mol Cell Biol 18: 758-770

Pei W, Noushmehr H, Costa J, Ouspenskaia MV, Elkahloun AG \& Feldman B (2007) An early requirement for maternal FoxH1 during zebrafish gastrulation. Dev Biol 310: 10-22

Petridou NI, Grigolon S, Salbreux G, Hannezo E \& Heisenberg C-P (2019) Fluidizationmediated tissue spreading by mitotic cell rounding and non-canonical Wnt signalling. Nat Cell Biol 21: 169-178

Petridou NI, Spiró Z \& Heisenberg C-P (2017) Multiscale force sensing in development. Nat Cell Biol 19: 581-588

Piccolo S, Dupont S \& Cordenonsi M (2014) The biology of YAP/TAZ: hippo signaling and beyond. Physiol Rev 94: 1287-1312

Porazinski S, Wang H, Asaoka Y, Behrndt M, Miyamoto T, Morita H, Hata S, Sasaki T, Krens SFG, Osada Y, et al (2015) YAP is essential for tissue tension to ensure vertebrate 3D body shape. Nature 521: 217-221

Reim G \& Brand M (2006) Maternal control of vertebrate dorsoventral axis formation and epiboly by the POU domain protein Spg/Pou2/Oct4. Dev Camb Engl 133: 2757-2770

Schlegelmilch K, Mohseni M, Kirak O, Pruszak J, Rodriguez JR, Zhou D, Kreger BT, Vasioukhin V, Avruch J, Brummelkamp TR, et al (2011) Yap1 acts downstream of $\alpha$ catenin to control epidermal proliferation. Cell 144: 782-795 
bioRxiv preprint doi: https://doi.org/10.1101/2020.12.01.407478; this version posted December 4, 2020. The copyright holder for this preprint (which was not certified by peer review) is the author/funder, who has granted bioRxiv a license to display the preprint in perpetuity. It is made available under aCC-BY-NC-ND 4.0 International license.

Silvis MR, Kreger BT, Lien W-H, Klezovitch O, Rudakova GM, Camargo FD, Lantz DM, Seykora JT \& Vasioukhin V (2011) $\alpha$-catenin is a tumor suppressor that controls cell accumulation by regulating the localization and activity of the transcriptional coactivator Yap1. Sci Signal 4: ra33

Solnica-Krezel L (2020) Chapter Thirteen - Maternal contributions to gastrulation in zebrafish. In Current Topics in Developmental Biology, Marlow FL (ed) pp 391-427. Academic Press

Song H, Luo Q, Deng X, Ji C, Li D, Munankarmy A, Jian W, Zhao J \& Fang L (2019) VGLL4 interacts with STAT3 to function as a tumor suppressor in triple-negative breast cancer. Exp Mol Med 51: 1-13

Song S, Eckerle S, Onichtchouk D, Marrs JA, Nitschke R \& Driever W (2013) Pou5f1dependent EGF expression controls E-cadherin endocytosis, cell adhesion, and zebrafish epiboly movements. Dev Cell 24: 486-501

Stooke-Vaughan GA \& Campàs O (2018) Physical control of tissue morphogenesis across scales. Curr Opin Genet Dev 51: 111-119

Sun Q, Liu X, Gong B, Wu D, Meng A \& Jia S (2017) Alkbh4 and Atrn Act Maternally to Regulate Zebrafish Epiboly. Int J Biol Sci 13: 1051-1066

Suo J, Feng X, Li J, Wang J, Wang Z, Zhang L \& Zou W (2020) VGLL4 promotes osteoblast differentiation by antagonizing TEADs-inhibited Runx2 transcription. Sci Adv 6: eaba4147

Ulrich F, Krieg M, Schötz E-M, Link V, Castanon I, Schnabel V, Taubenberger A, Mueller D, Puech P-H \& Heisenberg C-P (2005) Wnt11 functions in gastrulation by controlling cell cohesion through Rab5c and E-cadherin. Dev Cell 9: 555-564

Varshney GK, Carrington B, Pei W, Bishop K, Chen Z, Fan C, Xu L, Jones M, LaFave MC, Ledin J, et al (2016) A high-throughput functional genomics workflow based on CRISPR/Cas9-mediated targeted mutagenesis in zebrafish. Nat Protoc 11: 2357-2375

Veil M, Schaechtle MA, Gao M, Kirner V, Buryanova L, Grethen R \& Onichtchouk D (2018) Maternal Nanog is required for zebrafish embryo architecture and for cell viability during gastrulation. Development 145

Wagner DS, Dosch R, Mintzer KA, Wiemelt AP \& Mullins MC (2004) Maternal control of development at the midblastula transition and beyond: mutants from the zebrafish II. Dev Cell 6: 781-90

Wang Y, Liu X, Xie B, Yuan H, Zhang Y \& Zhu J (2020) The NOTCH1-dependent HIF1 $\alpha /$ VGLL4/IRF2BP2 oxygen sensing pathway triggers erythropoiesis terminal differentiation. Redox Biol 28: 101313

Wozniak MA \& Chen CS (2009) Mechanotransduction in development: a growing role for contractility. Nat Rev Mol Cell Biol 10: 34-43

Xu H, Li C, Zeng Q, Agrawal I, Zhu X \& Gong Z (2016) Genome-wide identification of suitable zebrafish Danio rerio reference genes for normalization of gene expression data by RT-qPCR. J Fish Biol 88: 2095-2110

Xue C, Liu X, Wen B, Yang R, Gao S, Tao J \& Zhou J (2019) Zebrafish Vestigial Like Family Member 4b Is Required for Valvulogenesis Through Sequestration of Transcription Factor Myocyte Enhancer Factor 2c. Front Cell Dev Biol 7: 277

Xue C, Wang HH, Zhu J \& Zhou J (2018) The expression patterns of vestigial like family member 4 genes in zebrafish embryogenesis. Gene Expr Patterns 28: 34-41

Yamaguchi N (2020) Multiple Roles of Vestigial-Like Family Members in Tumor Development. Front Oncol 10: 1266

Yang W, Wang Y, Jiang D, Tian C, Zhu C, Li G \& Chen H (2020) ddRADseq-assisted construction of a high-density SNP genetic map and QTL fine mapping for growth-related traits in the spotted scat (Scatophagus argus). BMC Genomics 21: 278 
Yap AS, Duszyc K \& Viasnoff V (2018) Mechanosensing and Mechanotransduction at CellCell Junctions. Cold Spring Harb Perspect Biol 10: a028761

Yu W, Ma X, Xu J, Heumuller AW, Fei Z, Feng X, Wang X, Liu K, Li J, Cui G, et al (2019) VGLL4 plays a critical role in heart valve development and homeostasis. PLoS Genet 15: e1007977

Zhang H, Pasolli HA \& Fuchs E (2011) Yes-associated protein (YAP) transcriptional coactivator functions in balancing growth and differentiation in skin. Proc Natl Acad Sci 108: 2270-2275

Zhang W, Gao Y, Li P, Shi Z, Guo T, Li F, Han X, Feng Y, Zheng C, Wang Z, et al (2014) VGLL4 functions as a new tumor suppressor in lung cancer by negatively regulating the YAP-TEAD transcriptional complex. Cell Res 24: 331-343 


\section{Figure legends}

Figure 1. Epiboly progression in MZvgll4 embryos is delayed. a) Bright field images of wt, MZvgll4a and MZvgll4a/MZvgll4b embryos at different developmental stages as indicated in the panels for wt embryos. Note the delayed epiboly (red brackets) and blastopore closure (red asterisks) as well as the increased distance between the EVL and DEL margins (yellow arrows) in MZvgll4a and MZvgll4a/MZvgll4b embryos as compared to wt. Blastopore closure (red arrow) in mutants occurs when wt embryos have initiated somitogenesis (red dotted line). At the 26 somite stage, the tail of mutants is still not fully elongated (red arrowheads). b) Lateral views of wt and MZvgll4a larvae at $3 \mathrm{dpf}$ (left) and graph (right) showing the quantification of the body length from wt, MZvgll4a, MZvgll4b, MZvgll4l and MZvgll4a/MZvgll4b larvae at 3dpf. Note that MZvgll4a, MZvgll4b and MZvgll4a/vgll4b but not MZvgll4l mutants are shorter that the wt. Kruskal-Wallis test. $* * * * \mathrm{p}<0.0001$. c, e) Confocal images of dorsally viewed wt and MZvgll4a blastulas at $75 \%$ epiboly stage, stained with $\beta$-catenin antibody and Hoechst to visualize cellular plasma membranes and nuclei, respectively. Settings for image acquisition were adjusted in each sample to visualize clearly the plasmamembranes, thus enhancing the mutant levels. d, f) Violin-plots of the cell area from embryos shown in c, e. Data in d represent $\mathrm{n}=252 \mathrm{wt}$ and $\mathrm{n}=232 \mathrm{MZvgll4a}$ cells from 8 and 7 blastulas, respectively. Mann-Whitney test. $p=0.0384$. Data in $f$ represent $n=431$ wt and n=611 MZvgll4a cells from 7 and 12 embryos, respectively at $75 \%$ epiboly stage. t-test, $\mathrm{p}<0.0001$.

\section{Figure 2. Zygotic vgll4a function is dispensable for timely embryonic growth. a, c)}

Schematic representation of the mating strategy used to obtain embryos of the desired genotypes with or without vgll4a maternal contribution. b, d) Box plots of the body length from $3 \mathrm{dpf}$ larvae of the indicated genotypes. Note the decreased body length only in embryos with absent or haplo-insufficient maternal vgll4a contribution as compared to wt. The number of analyzed embryos is indicated below each plot. Data in $b$ were analyzed with Kruskal-Wallis test. $* * * *$ p $<0.0001$, whereas those in d) with One-Way ANOVA. ns, not significant. $* * * \mathrm{p}<0.001$. $* * * * \mathrm{p}<0.0001$.

Figure 3. Vgll4a acts upstream of yap activity to promote embryonic growth. a) Schematic representation the experimental design. b-e) Box plots of the body length from wt (b), MZvgll4l (c), MZvgll4a (d) and MZvgll4a;MZvgll4b (e) embryos grown in 
the presence of verteporfin or DMSO. Note that the drug has no effect on the already reduced body length of MZvgll4a and MZvgll4a;MZvgll4b larvae but reduces that of wt and MZvgll4l larvae. Data were analyzed with Mann-Whitney test. In b, c, d and e significance is as follow: $p<0.0001 ; p=0.0012 ; p=0.5706$ and $p=0.6064$. f, g) The graphs show the expression level of the Yap-TEAD transcriptional target $c c n l$ at sphere and $75 \%$ epiboly stage in wt and MZvgll4a embryos as determined by Q-RT-PCR analysis. Note the significant reduction of $c c n l$ expression in the mutants. $t$ test. $\mathrm{p}=0.0042$ in $\mathrm{f}$ and $\mathrm{p}=0.0746$ in $\mathrm{g} . \mathrm{ns}$, not significant, $* * \mathrm{p}<0.01 ; * * * * \mathrm{p}<0.0001$.

Figure 4. Maternal vgll4a is required for proper organization of the actomyosin ring. a-d') Confocal images of wt and $M Z v g l l 4 a$ embryos at $75 \%$ epiboly stage (lateral views) stained with phalloidin and Hoechst to visualize F-actin and nuclei, respectively. Note that the actomyosin ring in MZvgll4a embryos is thinner (white brackets in $\mathrm{a}^{\prime}, \mathrm{b}^{\prime}$ ) and rather separated from the DEL margin (yellow arrows in a, b) as compared to wt embryos. Note also that F-actin distribution of EVL cells in MZvgll4a embryos is ruffled and disorganized (yellow arrowheads in $\mathrm{d}^{\prime}$ ) in contrast to the well aligned distribution in wt embryos. Asterisk in $\mathrm{d}, \mathrm{d}^{\prime}$ indicates loss of cell-cell contacts. e, f) Quantification of the actomyosin ring width and DEL-EVL distance in wt $(n=24)$ and MZvgll4a (n=34) embryos (Mann-Whitney test. ****, $\mathrm{p}<0.0001)$. g) The graphs show the expression level of arhgap18 transcripts in MZvgll4a and wt embryos at $75 \%$ epiboly stage (t-test. $\mathrm{p}=0.041$ ), as determined by qRT-PCR analysis. ${ }^{*}, \mathrm{p}<0.05$. Scale

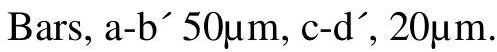

Figure 5. Maternal vgll4a is required for plasma membrane localization of the Ecadherin//-catenin complex. a, i) Schematic representation of the different imaging strategies. b-g; j-o) Confocal images of F-actin (b, e, j, m), $\beta$-catenin (c, g, k, n) and Ecadherin $(\mathrm{d}, \mathrm{g}, \mathrm{l}, \mathrm{o})$ distribution in EVL (b-g) and DEL (j-o) cells in wt and MZvgll4a embryos at sphere stage. Embryos were counterstained with Hoechst (nuclei, green). h, p) The graphs depict the fluorescent signal intensity (in arbitrary units, a.u) for F-actin, $\beta$-catenin and E-cadherin in EVL (h) or DEL (p) cells of wt and MZvgll4a embryos (Mann Whitney test. h) E-cadherin; $\mathrm{p}=0.0425$. p) F-actin, $\mathrm{p}=0.3154 ; \beta$-catenin, $\mathrm{p}=0.0005$ and E-cadherin, $\mathrm{p}=0.1087$. ns, not significant, $* \mathrm{p}<0.05 ; * * * \mathrm{p}<0.001$; $* * * *$ $\mathrm{p}<0.0001$. Scale bar, $10 \mu \mathrm{m}$.

Figure 6. Proposed model for maternal vgll4a contribution to zebrafish epiboly progression. Maternal vgll4a promotes plasma membrane localization of the E- 
cadherin $/ \beta$-catenin complex in the amount required for an adequate cohesion among blastomeres. This cohesion threshold allows tissue mechano-sensing and thus yap1dependent mechano-transduction. Signal transduction impacts on the organization and function of the actomyosin ring, thereby promoting timely epiboly progression. E-cad, E-cadherin; $\beta$-cat, $\beta$-catenin; F-act, F-actin. 







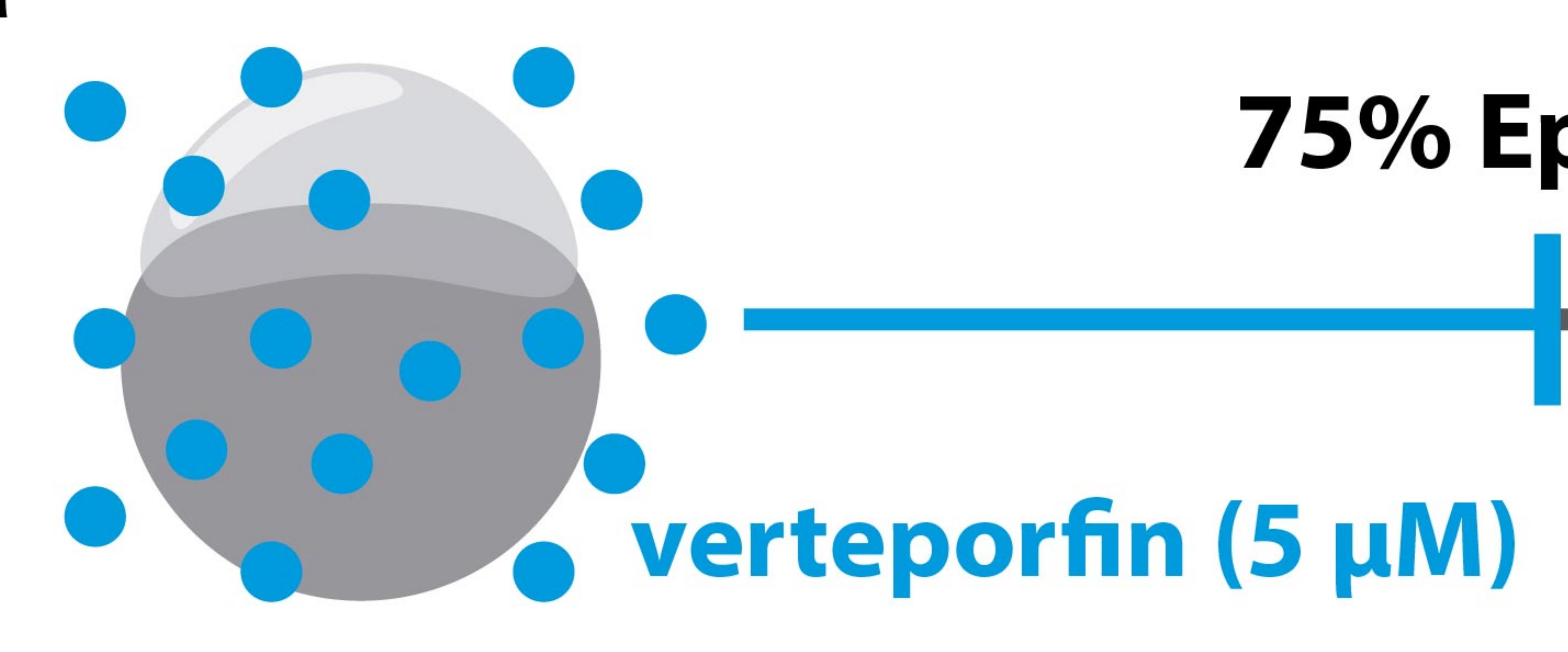

b
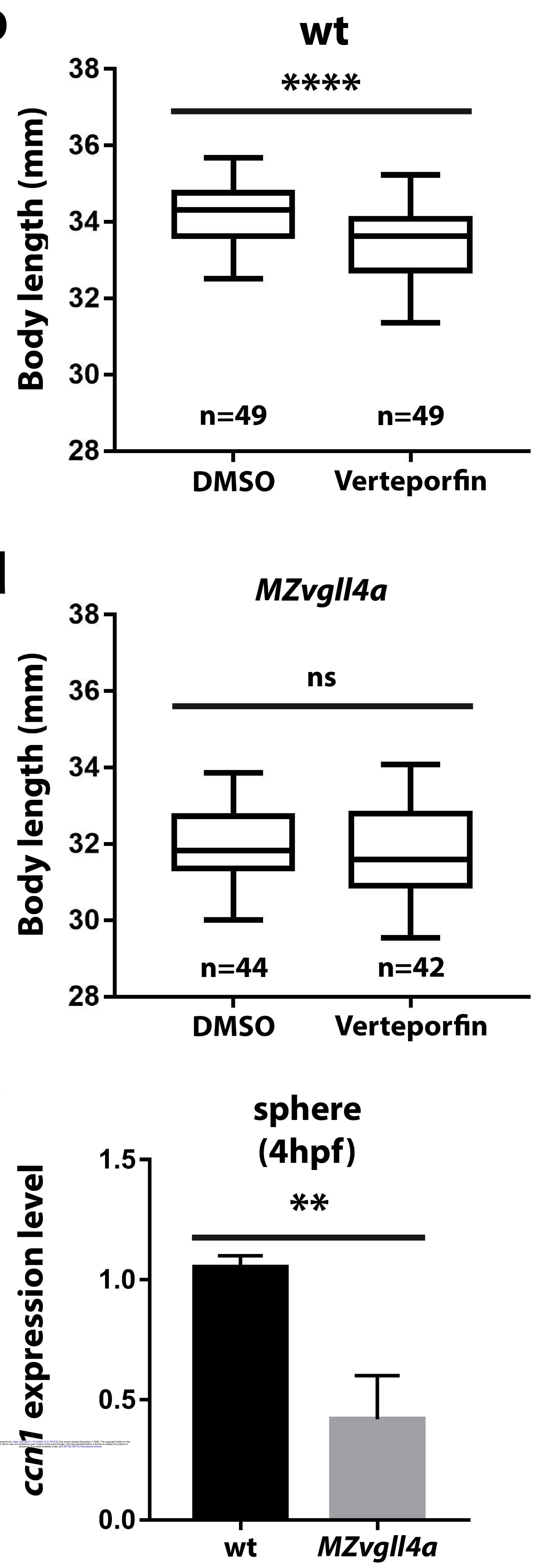

Body length (mm)

C

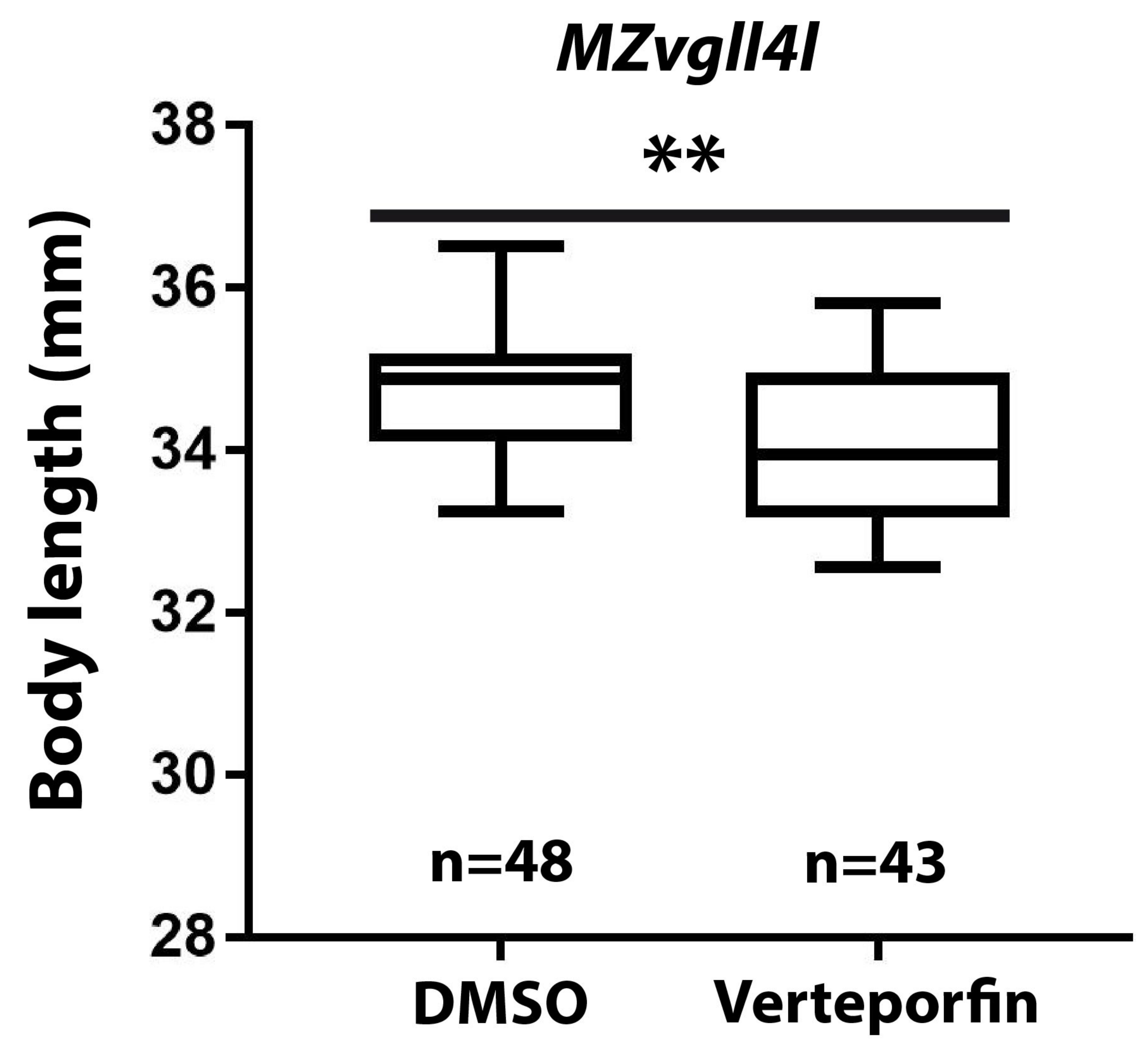

e

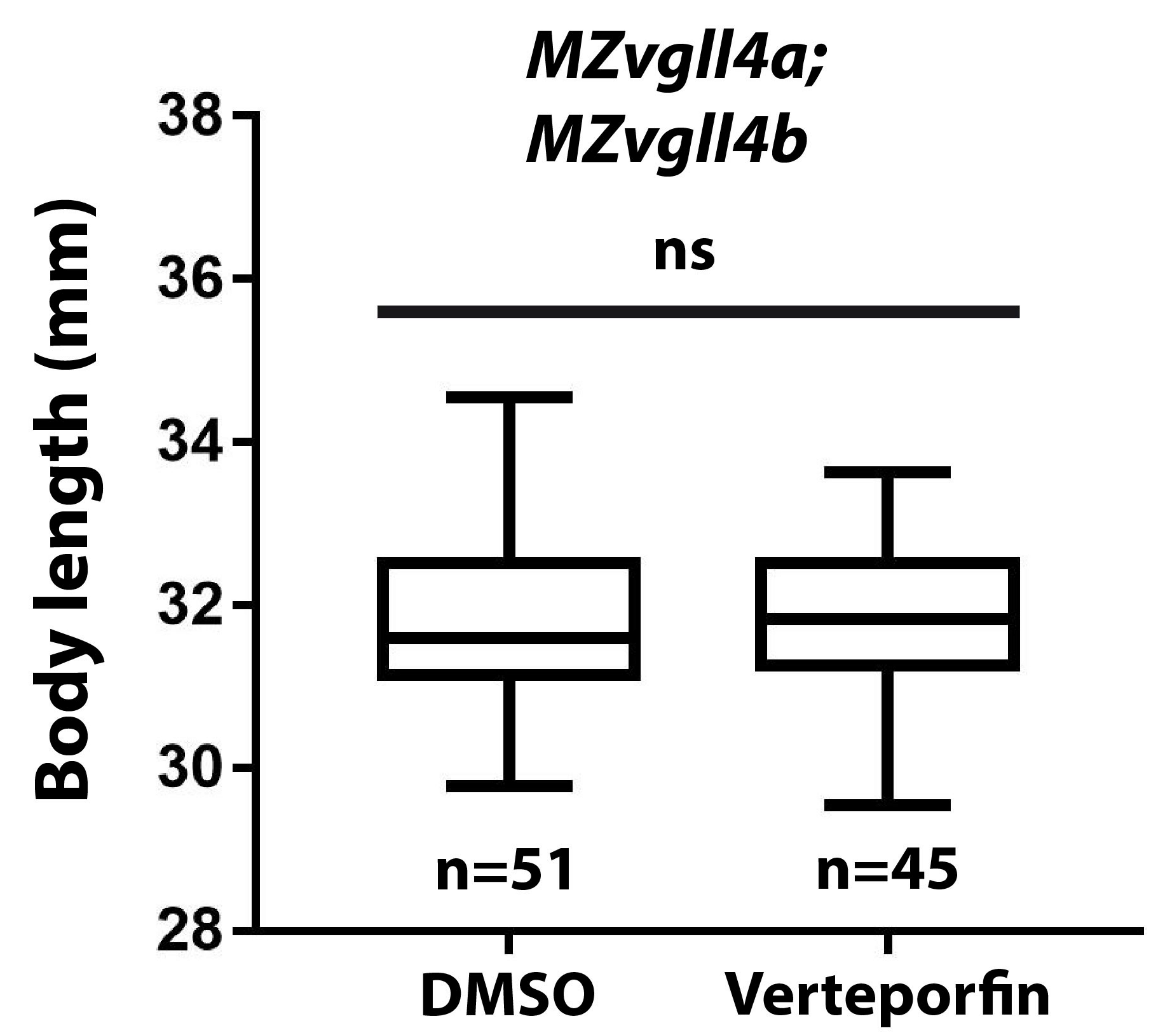

g

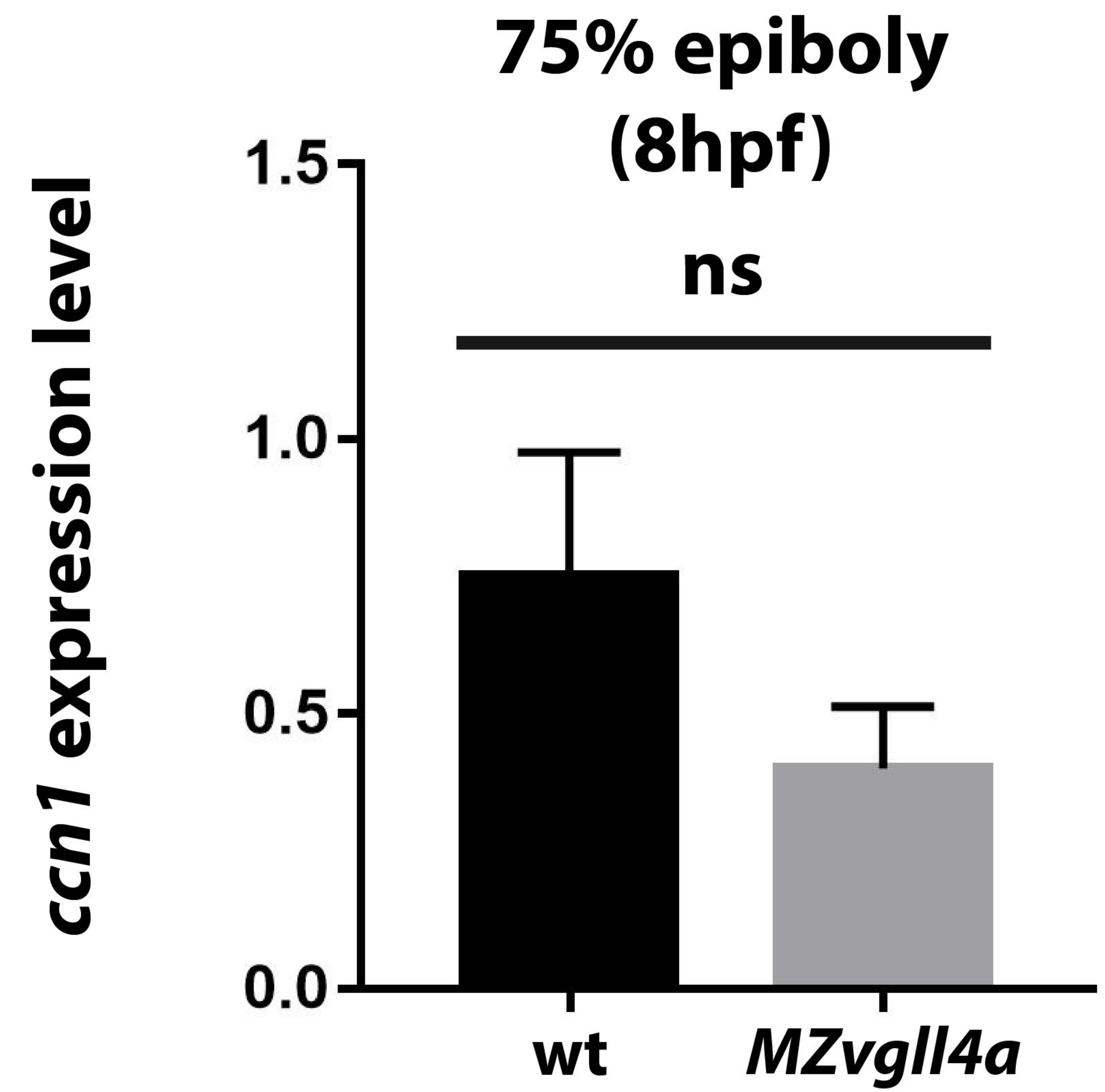

\section{Figure 3}




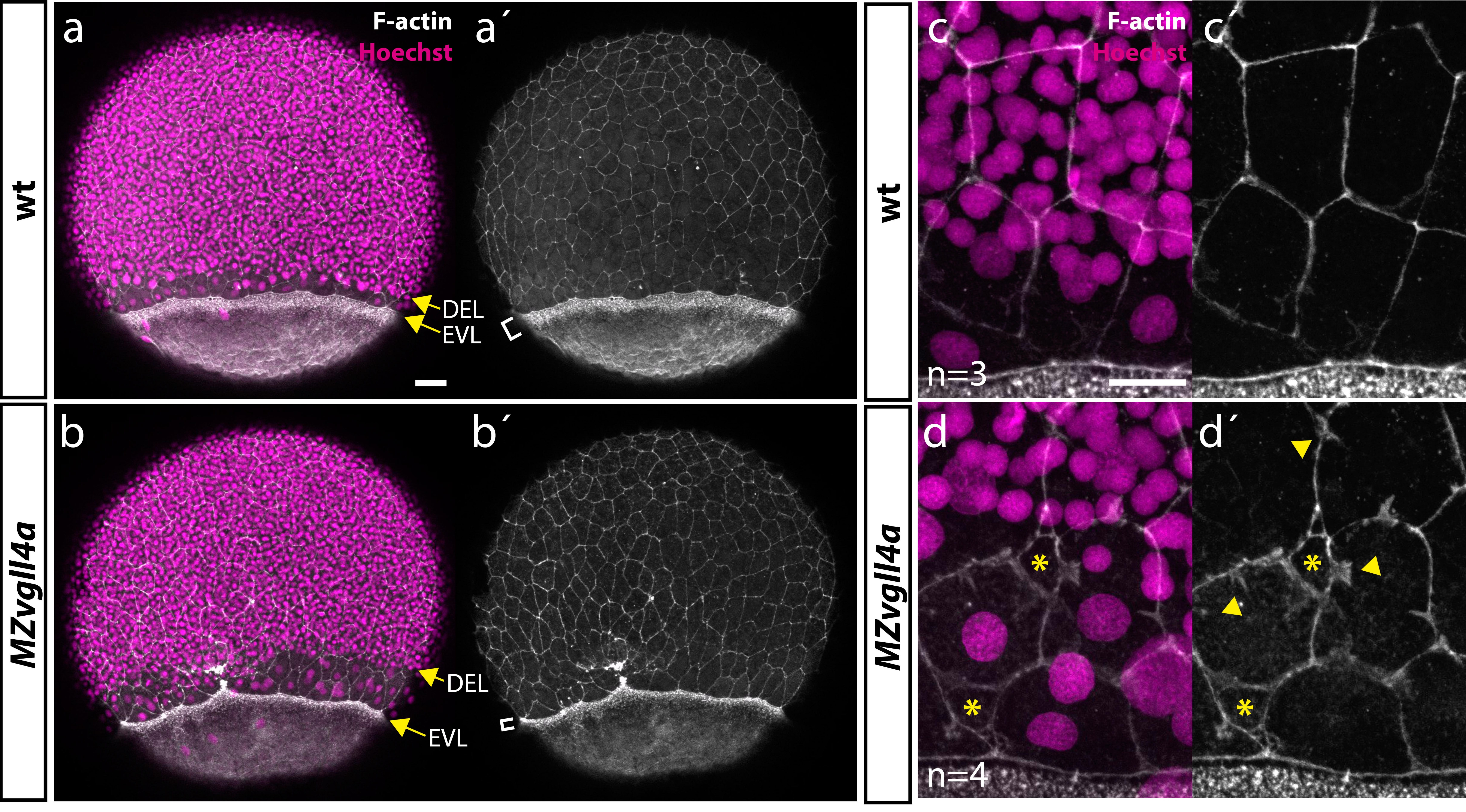

e

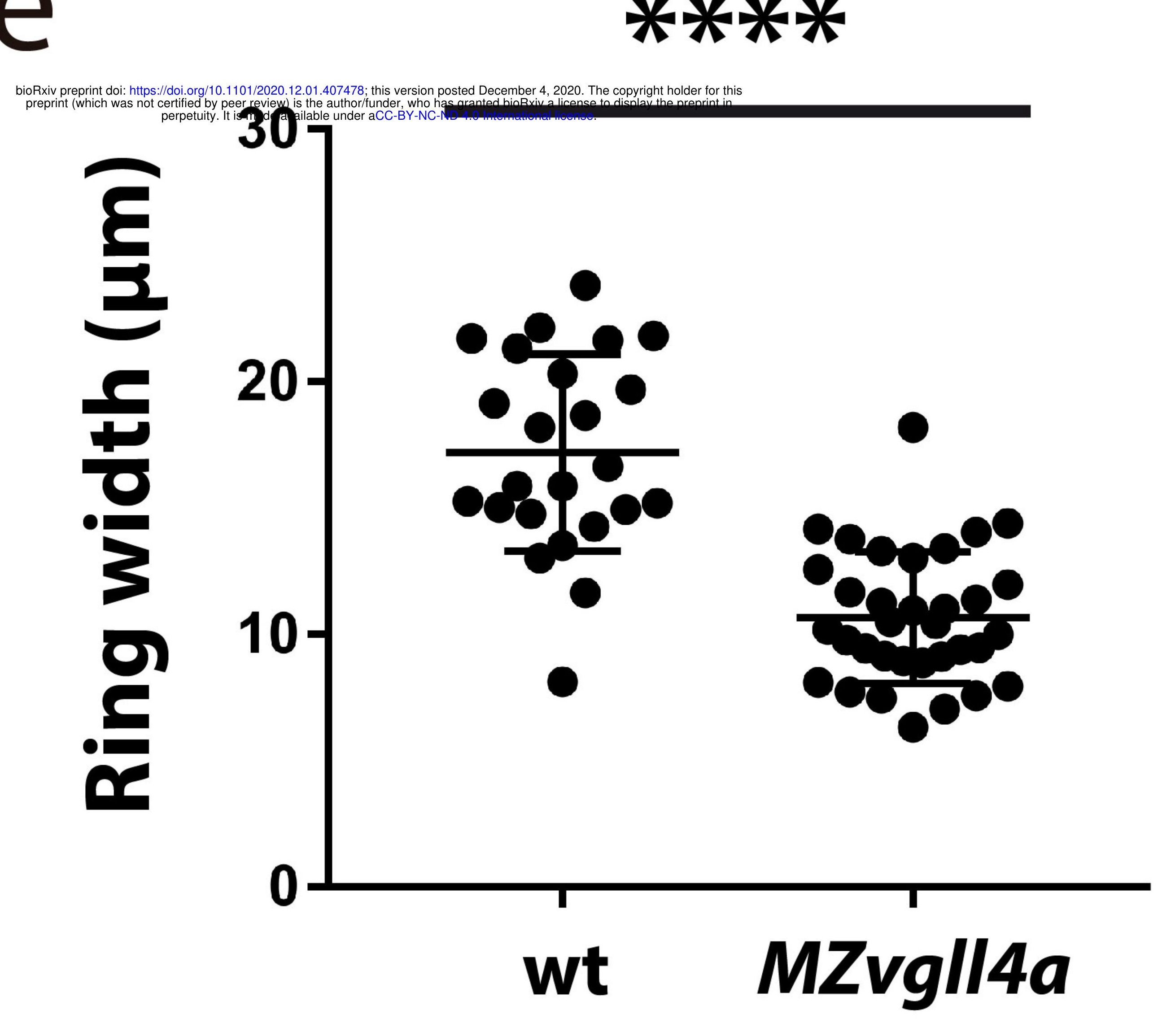

敌

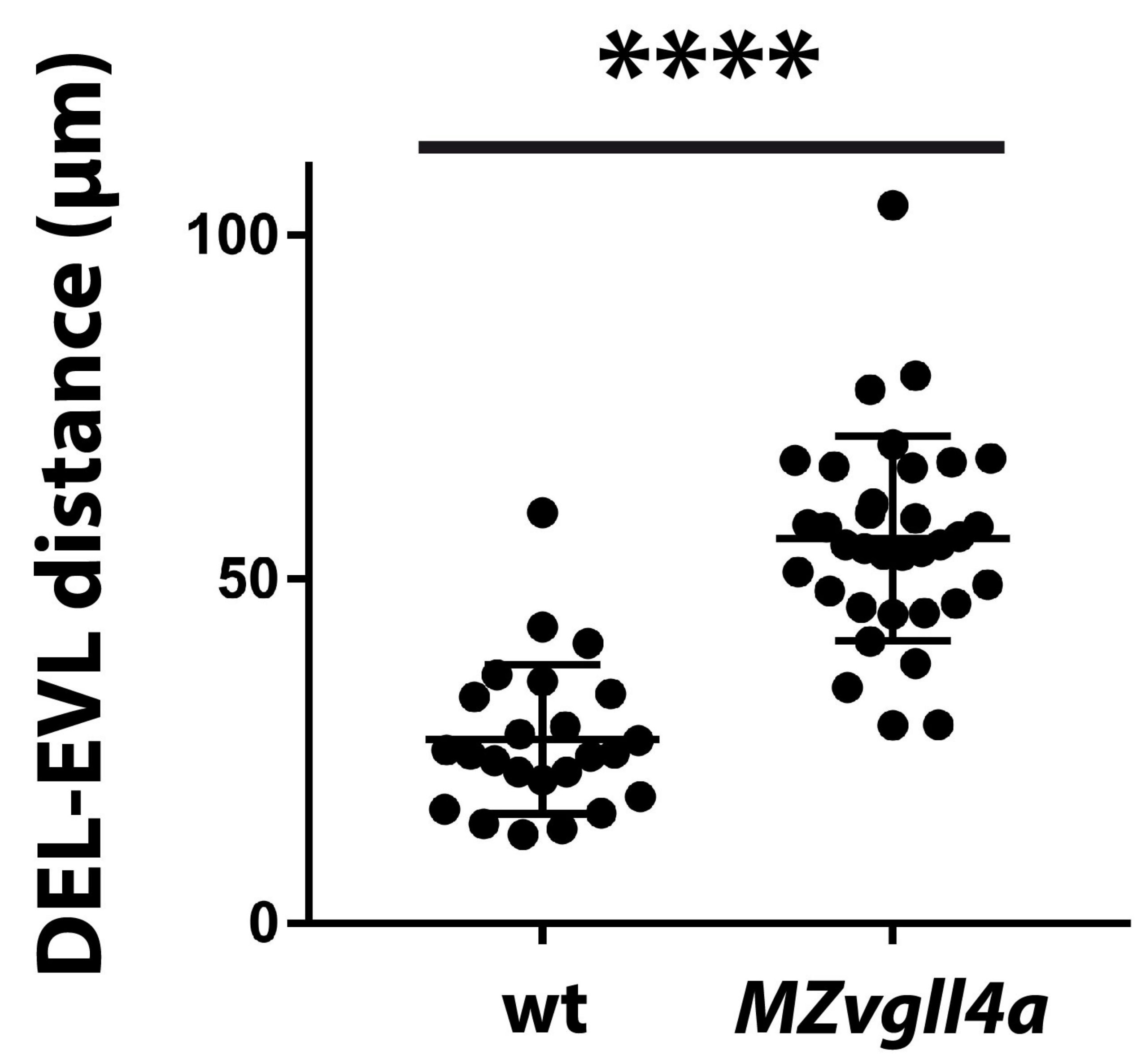

9

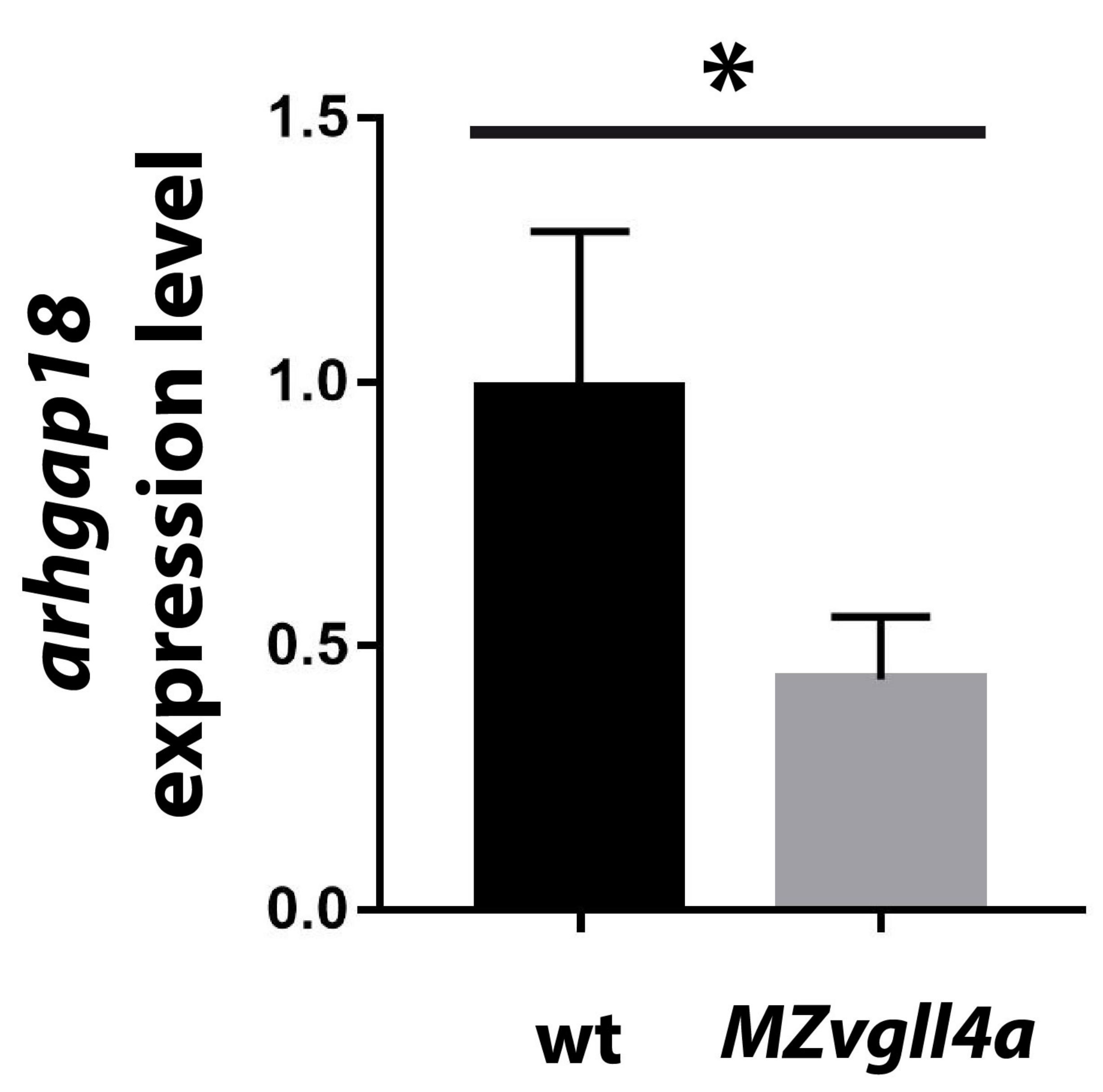

\section{Figure 4}




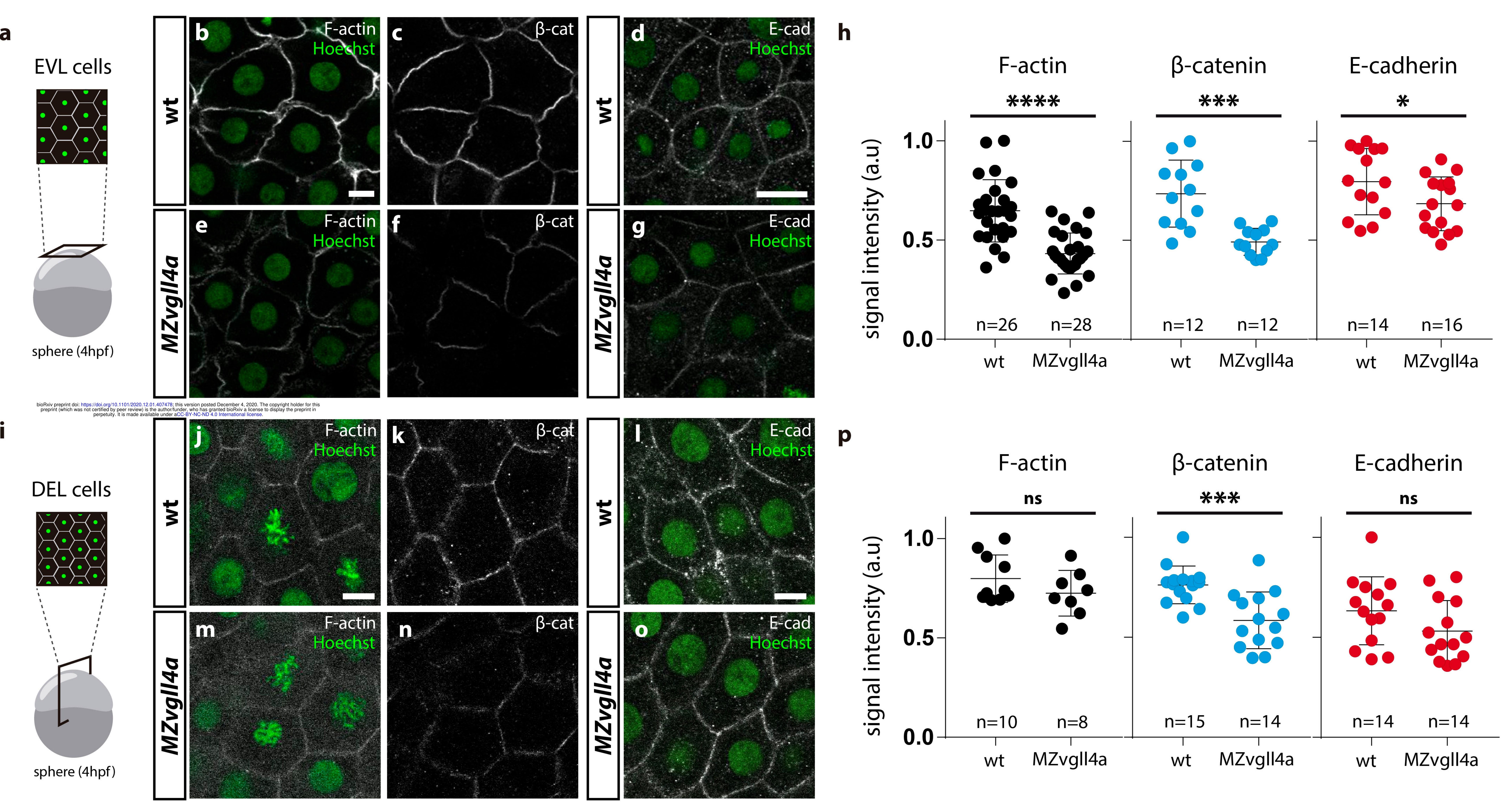

Figure 5 
mechanotransduction 